\title{
A Geospatial Analysis of Bark Beetle-Induced Wildfire Risk Zones in the Okanogan Wenatchee National Forest
}

\author{
Marco Allain ${ }^{1, *}$, Andrew Nguyen ${ }^{2}$, Evan Johnson ${ }^{3}$, Emily Williams ${ }^{4}$, Stephanie Tsai ${ }^{5}$, \\ Susan Prichard ${ }^{6}$, J. W. Skiles ${ }^{7}$ \\ ${ }^{1}$ Department of Earth Science, Emporia State University, Emporia, USA \\ ${ }^{2}$ Department of Geography, San Jose State University, Fremont, USA \\ ${ }^{3}$ Department of Geography, University of California, Los Angeles, Los Angeles, USA \\ ${ }^{4}$ Department of Environmental Studies, University of California, Santa Barbara, USA \\ ${ }^{5}$ Department Computer Science, Stanford University, Stanford, CA, USA \\ ${ }^{6}$ Pacific Wildland Fire Sciences Laboratory, USDA Forest Service, Seattle, USA \\ ${ }^{7}$ National Aeronautic Space Administration, NASA Ames Research Center, Mountain View, USA
}

\author{
Email address: \\ marcoallain006@outlook.com (M. Allain), andrew.nguyen@nasa.gov (A. Nguyen), erjohnson@ucla.edu (E. Johnson), \\ ewilliams@umail.ucsb.edu (E. Williams), stsai612@stanford.edu (S. Tsai), sprich@u.washington.edu (S. Prichard), \\ joseph.skiles@nasa.gov (J. W. Skiles) \\ ${ }^{*}$ Corresponding author
}

\section{To cite this article:}

Marco Allain, Andrew Nguyen, Evan Johnson, Emily Williams, Stephanie Tsai, Joseph Skiles, Susan Prichard. A Geospatial Analysis of Bark Beetle-Induced Wildfire Risk Zones in the Okanogan Wenatchee National Forest. Agriculture, Forestry and Fisheries.

Vol. 6, No. 1, 2017, pp. 34-44. doi: 10.11648/j.aff.20170601.15

Received: December 28, 2016; Accepted: January 21, 2017; Published: March 2, 2017

\begin{abstract}
Over the past 30 years mountain pine beetle (MPB) outbreaks have become widespread throughout the western US and Canada. MPB attacks leave acres of dead trees that may predispose forest landscapes to large fires. With the use of field work and geospatial technology, these outbreaks can be better mapped and assessed to evaluate forest health. This study is designed to map and classify bark beetle infestation in Washington's Wenatchee National Forest. Field work on seventeen randomly selected sites was conducted using the point-centered quarter method. Recent MPB outbreak areas were classified using National Agriculture Imagery Program (NAIP) imagery. A link between MPB attack and forest fires was then quantified using MODIS fire data. Lastly, a predictive infestation model was constructed using the following geophysical parameters: disturbance indices, Landsat TM5 classification of groundcover as well as vegetation stress using hyperspectral data. Selected imagery from the Hyperion sensor was used to run a minimum distance supervised classification in ENVI, in attempt to detect the early "green stage" of infestation. This study detected MPB spread and assessed the fire risk related to infestation.
\end{abstract}

Keywords: MODIS, Bark Beetle Infestation, GIS, Wildfire, Spectral Indices

\section{Introduction}

A legacy of fire exclusion and increased incidence of summer drought in the western US has predisposed forested landscapes to bark beetle outbreaks [15, 1]. Bark beetles such as the mountain pine beetle Dendroctonus ponderosae have spread rapidly over the past few decades [24]. Since bark beetles kill the tree they infest, increased infestations result in an abundance of dead biomass, which may lead to increased risk of wildfires [33].

From the West Coast through the Rocky Mountains, bark beetles have affected more than 41.7 million acres of conifer forests [21]. Bark beetles preferentially attack trees that showcase two favorable characteristics; nutrient content and trunk diameter thickness [32]. These factors are thought to attract beetles which then bore into trees and deposit their larvae. Bark beetles are most successful when attacking trees that have been weakened by disease, drought, smog, previous infestations or physical damage. These attacks further 
weaken the trees, leading to stem deformities, loss of growth, and premature mortality [31].

The mountain pine beetle (Dendroctonus ponderosae), targets ponderosa and lodgepole pines in the western US and Canada [10]. Healthy trees secrete resin which contains insecticidal and fungicidal compounds. Such compounds defend the tree against beetle infestations, immobilizing and suffocating the beetles. However, a heavy infestation can overwhelm these defenses, especially in weakened trees, resulting in sawdust-like shavings around the entrance holes (Figure 1), [24]. Prolonged drought can weaken tree defenses and make them more susceptible to attack [25].

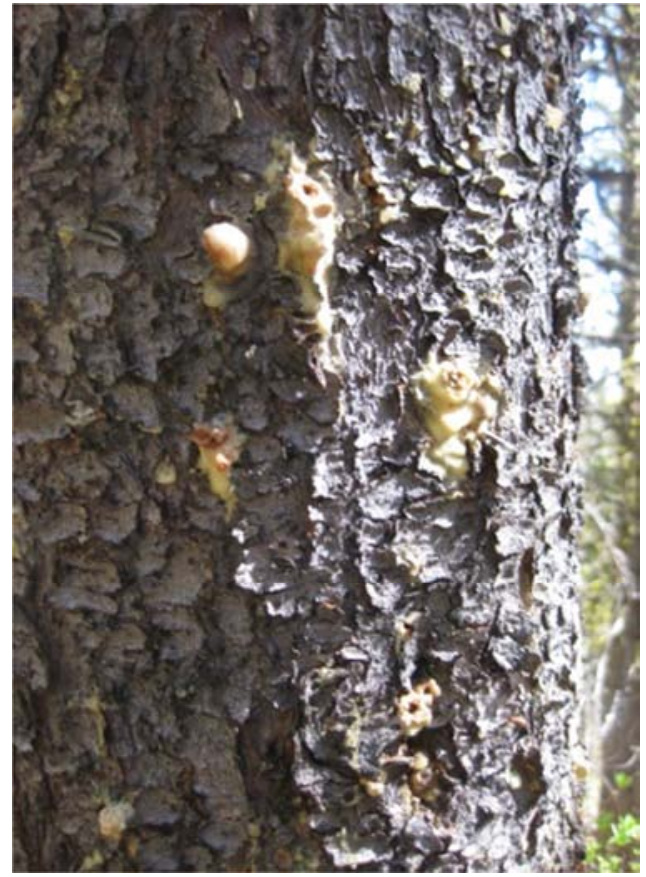

Figure 1. Trees produce sap as a defense mechanism when bark beetles borough into the tree, creating pitch tubes.

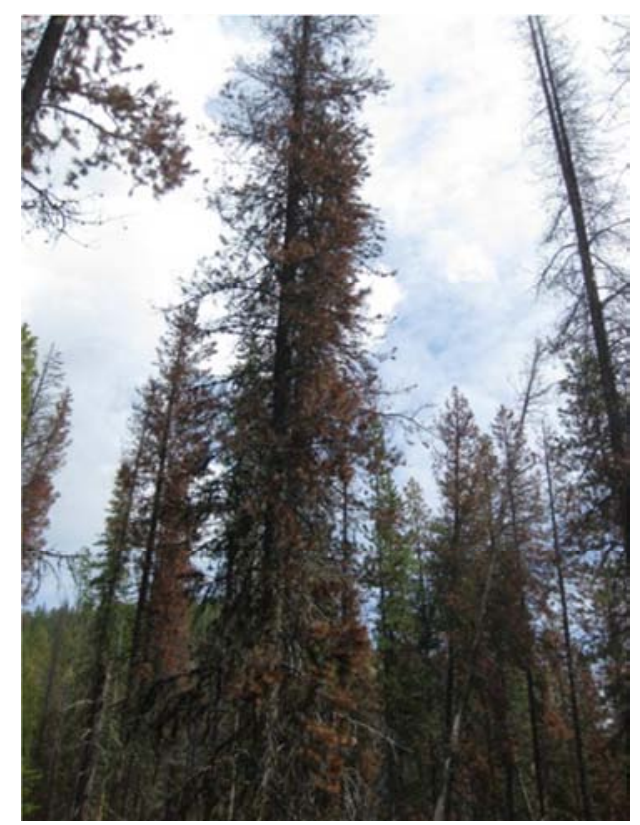

Figure 2. A red phase tree.

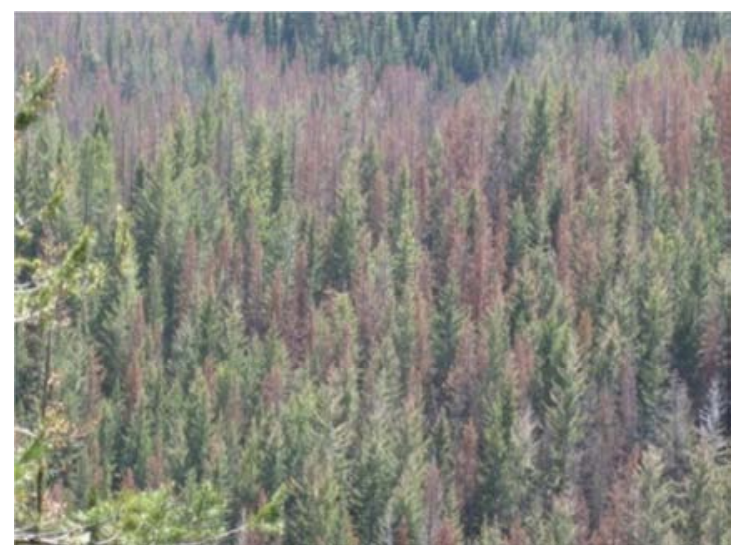

Figure 3. A mix of green, red, and gray phase trees.

Tree infestation is a three-stage process (Figure 3). Green attack, the first stage, shows no color change and is therefore difficult to detect with remote sensing. During this stage, the beetles begin to burrow through the phloem, interrupting the nutrient flow. It takes roughly one year to transition to the second stage, red attack, which can be detected by satellite sensors (Figure 2). The beetle larvae begin to feed on the tree's phloem, starving the tree of nutrients and water, and changing the crown from green to yellow to red. Lack of water and nutrient flow eventually kills the tree. Gray attack is the final stage in which the tree is dead and has lost all foliage [32].

Ground surveys, remote sensing techniques, and aerial detection surveys are the primary methods for monitoring bark beetle infestations and wildfires [43]. However, ground surveys are costly and time consuming. Satellite remote sensing methods have proved to be economical tools for detecting forest damage, in areas where bark beetles have caused uniform pockets of damage and where fires are widespread. However, outbreaks are rarely homogeneous in age and tree species, and most outbreaks are not large enough to be remotely detected [28]. These factors impair the accuracy of remote sensing classification models [18]. As a result, it is difficult to understand the magnitude of the problem by exclusively examining satellite imagery. Using multiple remotely sensed images coupled with ground-based validation can be a promising approach to better understand this problem.

The objective of this study was to map the extent of the bark beetle infestation in the Okanogan-Wenatchee National Forest in northern Washington State. We used a suite of ground-based and remotely sensed datasets to: (1) map an ongoing MPB outbreak and train MPB classifications of satellite imagery with field data; (2) analyze the relationship between bark beetles and forest fires by comparing the previously determined infestation sites with locations of known fires; and (3) predict future outbreak areas based on disturbance indices and hyperspectral satellite data. Through field work and, remote sensing image analysis and an understanding of the incipient phase, this study identifies specific present and future regions of MPB outbreaks [32, 34]. 
The study area is Washington's Okanogan-Wenatchee National Forest and is located directly south of the Canadian border and east of Cascades National Park in central Washington State (Figure 4). Field sites were located within a $4 \mathrm{~km}$ radius of 48.09 latitude and -120.19 longitude. Vegetation within the forest is variable, with small shrubs and grasslands covering the lower elevations. Mid-elevation vegetation primarily consists of ponderosa pine (Pinus ponderosa) and Douglas fir (Pseudotsuga menziesii) [36], while lodgepole pine (P. contorta), Engelmann spruce (Picea engelmanii), and subalpine fir (Abies lasiocarpa) [26] dominate higher elevation forests above 1,800 meters.

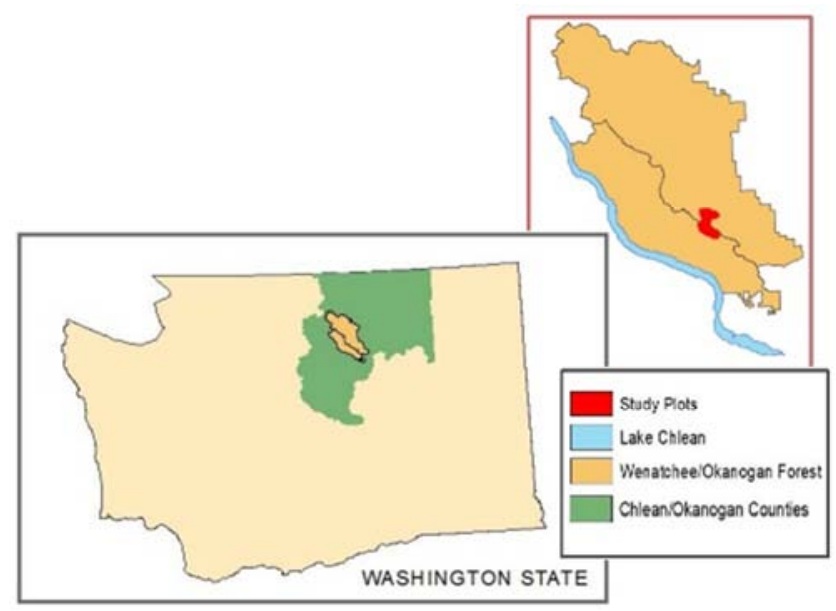

Figure 4. Our study site was located in Washington State, directly above Lake Chelan.

Climate is characterized by moderate temperatures during the summer and occasional sub-zero temperatures during the winter months [22]. Recent droughts in 2001 and 2005 are characterized by decreased seasonal precipitation. Mean annual precipitation ranges from 30 to 230 centimeters [39]. In recent years, the region experienced prolonged droughts in 2001 and 2005 and a number of severe wildfire years. The Deer Point Fire of August 2002 burned stands on the south western edge of our study region. The Tripod Fire burned in excess of 70,820 hectares of the Okanogan wilderness, ranking as one of the largest fires in Washington State over the past 50 years. Before American settlement, Washington's surface fires decreased the long-term threat of running crown fires by reducing the fuel bed [23]. These fires reduced competition for site resources among surviving trees, shrubs, and herbs. Large extant dry forests no longer appear as they did. Modern landscapes are homogeneous and set up for severe, large fire and insect disturbance events [16].

\section{Methodology}

\subsection{Bark Beetle Infestation Detection}

\subsubsection{Field Work}

A field study was conducted in June of 2010 to classify forest stands in various stages of attack. This classification established a base to quantitatively determine percent infestation and, provided a means to accurately assess satellite data. Seventeen sampling units were measured, each within one of the following categories - severe (red-attack or gray-attack), moderate, and not attacked. Sampling sites were randomly generated, located in polygons derived from known MPB outbreak areas in 2009 Forest Service Aerial Surveys [40]. Selected sites were at least 90 meters and no farther than 500 meters from established roads.

The center of each sampling unit was located using a realtime differential correction on a Trimble GPS unit. Each coordinate was checked using a Garmin ETrex Vista Hcs handheld GPS. Units are 60x60 meters, each consisting of 12 subplots spread across a grid [7]. Subplots consist of three columns spread an equidistant 15 meters apart, with four rows spread at various distances; 10 meters from the northern edge to the first row, 12.5 meters to the second row, 15 meters to the third, 12.5 meters to the fourth, and 10 meters to the southern edge (Figure 4). A laser range finder was utilized to measure the distance from subplot center to the sampled tree. The pointcenter quarter method [30] defines each subplot, in which the four geographical bearings (north, east, south and west) tagged which trees to sample (Figure 5). Measurements taken at each tree included diameter at base height $(\mathrm{DBH})$, distance from sub-plot center, tree species, percent red attack, percent gray attack, and presence of pitch tubes or noticeable resin secretions. This dataset chronicles tree density, species composition, and percent of trees attacked, displaying three or more pitch tubes. Further measurements were noted at each plot for percent groundcover, percent understory coverage, and percent over-story coverage.

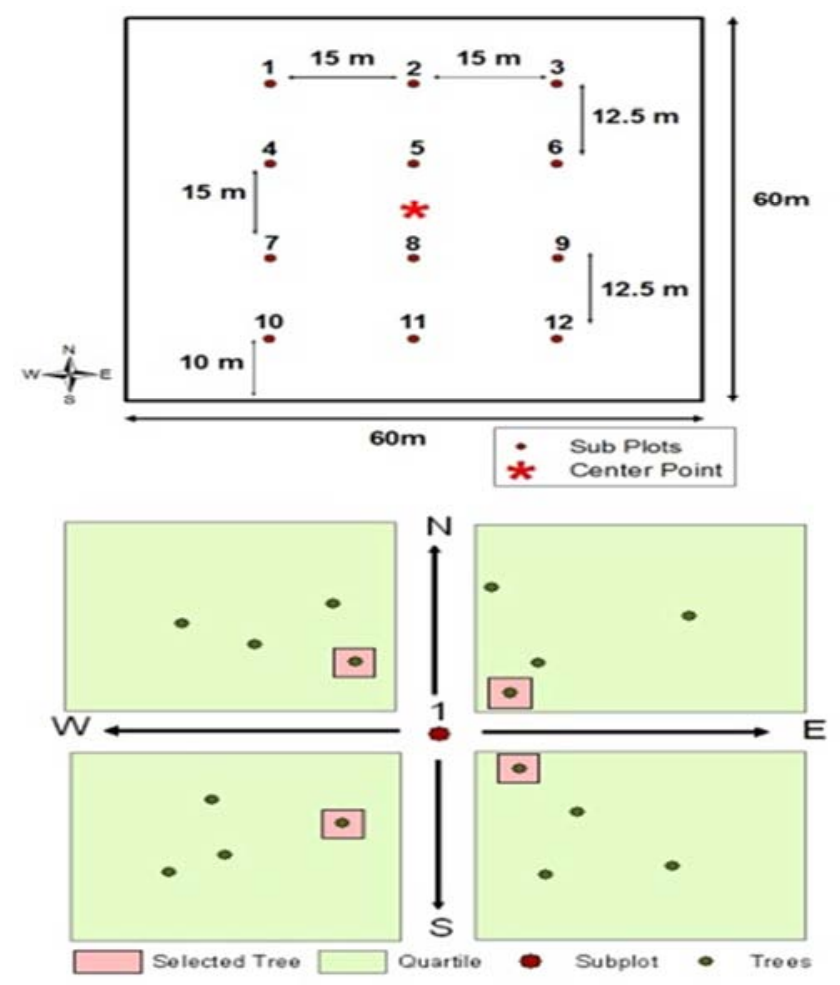

Figure 5. An illustration of the point-centered field sampling method [30]. 


\subsubsection{Landsat Classification}

Sampling units were used to train classification of MPB outbreaks from Landsat Thematic Mapper 5 (TM5) and NAIP imagery. Landsat TM 5 is an orbiting sensor that provides 30 meter spatial resolution [34] images. Ten Landsat TM5 images were selected for this study and are representative of summer months (June-July) over 2002 to 2009 (http://glovis.usgs.gov/). Multiple images allowed multi temporal analyses to be performed. All images were radiometrically corrected in ERDAS Imagine 9.3 and then converted into reflectance values using the surface method [40, 4].

In order to assess the ability of Landsat to detect red-phase trees, an ISODATA unsupervised classification was conducted in ERDAS Imagine. LANDSAT data have three bands in the visible and one band in the near infrared part of the electromagnetic spectrum, enabling detection of land change patterns. The unsupervised, rather than the supervised, classification technique was chosen because the methodology could easily be recreated. For maximum precision of cluster building, 100 iterations were used with a convergence threshold of 0.995 . The band combination of 421 (RGB), offers enhanced discrimination of land-water boundaries and highlights topographic details which helped to differentiate between the classes [9]. Twenty classes were initially specified and zero values were ignored in the output. Vegetation classes were narrowed to four categories - healthy forest, red-phase forest, bare ground and shrublands, and ice [42]. Field work and NAIP photography were used to assign the four classes.

Aerial photography was used to asses to the accuracy of the classification. Accuracy assessments in remote sensing are performed by selecting a number of points in the classified image and checking them against reference data such as aerial photos. The binomial probability theory equation was utilized to determine the number of points that should be selected for the accuracy assessment [19]. The equation is defined below:

$$
N=\frac{Z^{2}(p)(q)}{E^{2}}
$$

This was computed where $N$ is the sample size, $Z=2$ from the standard deviate of 1.96 for the $95 \%$ two-sided confidence level, $p$ is the expected accuracy for the entire map, $q=100-p$, and $E$ is the allowable error [19]. The number of random sample locations was computed as 75 points with an expected accuracy of $75 \%$ and a $10 \%$ allowable error.

The above equation resulted in 80 points. Using equalized random point selection, eighty points were randomly placed in the classified image to ensure that each class received exactly ten sample points. Then, so that these datasets could be referenced, these same points were also placed on the mosaic. The mosaic was the true or 'reference' dataset against which the classification was checked. Once the process was complete, the accuracy statistics for each land cover type and for the overall classification, which is the combined mean of all land cover types, were collectively computed.

\subsubsection{Using NAIP Imagery to Quantify the Infestation}

The National Agriculture Imagery Program (NAIP) provides detailed, high resolution images acquired by aircraft of the entire United States. As Coggins et al showed digital aerial photography is useful for visualizing and quantifying the extent of the mountain pine beetle infestation as a result of its high spatial resolution. Each NAIP image contains spatially detailed ground information, allowing differentiation between red and green crowns. Red pixels have higher values in the multispectral NAIP imagery than do green pixels. A basic algorithm was used to identify red crown pixels based on visual inspection of the imagery (Equation 4).

$$
\left\{\left[\left(\frac{\operatorname{Re} d}{\text { Green }}\right)>\left(\text { Threshhold }_{\mathrm{Re} d / \text { Green }}\right)\right] *\left[\text { Blue }_{\text {Threshhold }} \text { Blue }\right]\right\} *[255]
$$

ERDAS Imagine was used to create a model which runs a raster NAIP image from a particular year through this algorithm. This process was performed with several images, but the image used in the accuracy assessment was taken in June of 2009 and consisted of two NAIP scenes. It is important to recognize that every NAIP image will have different threshold values dependent on the quality and time of day of the image. The algorithm sets to zero all pixels that do not meet the specified characteristics as defined by the unique threshold value. Such manipulation permits the creation of detailed maps that chronicle the amount of trees with red crowns in a given area. With one meter resolution, outbreak areas can be calculated based upon the number of red pixels in a given area. Again, the binomial probability theorem was used to assess the accuracy of the classification.

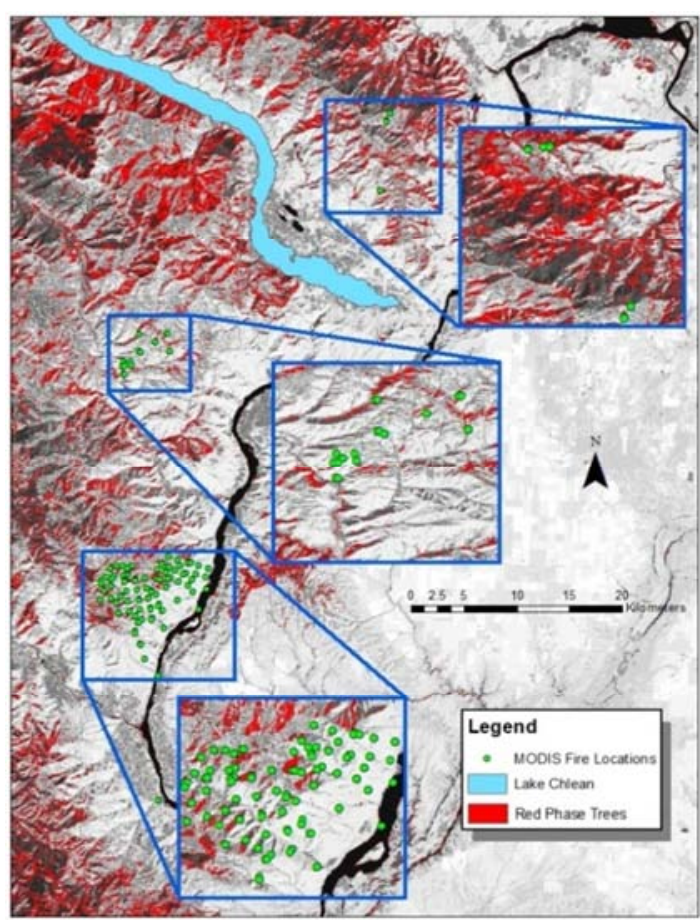

Figure 6. An illustration of satellite imagery from the MODIS Active Fire Product which was used to determine sites of bark beetle infestation in the Wenatchee National Forest. 


\subsection{Wildfire Analysis}

Once MPB outbreak areas could be readily identified, relationships between bark beetle outbreaks and incidence of wildfires could be further examined. The Moderate Resolution Imaging Spectroradiometer (MODIS) onboard the EOS Terra and Aqua satellites are capable of active fire detection and mapping. Terra's orbit around the Earth is timed so that it passes from north to south across the equator in the morning, while Aqua passes south to north over the equator in the evening. Aqua MODIS and Terra MODIS are viewing the entire Earth's surface every one to two days [3]. Active fire detection maps the flaming front of fires at the time of the satellite overpass and is possible because radiant energy increases with temperature, producing a high contrast between fire pixels and cool surrounding non-fire pixels.

Hawbaker, et al. found MODIS active fire data to be nearly $82 \%$ accurate. MODIS detected every fire larger than 2638ha. Regionally (East, Great Plains and Western US) [35] cloud cover effects on Terra or Aqua fire detections were most pronounced in the Eastern seaboard. Cloud effects were minimal in the Western US [14]. This could explain why MODIS fire detection rates are highest in the West. Thus, the Washington study site is ideal for MODIS data.

MODIS Terra and Aqua data were acquired from the Land Processes Distributed Active Archive Center (LPDAAC, http://edcdaac.usgs.gov/modis/dataproducts.asp). MODIS active fire pixels were overlaid atop the classified 2009 NAIP imagery (Figure 6). The previously derived algorithm (Equation 4) was used to determine outbreak areas. The area covered includes the region south of Lake Chlean in the original NAIP image. All detected fires in the study area were considered either bark beetle or non-bark beetle related. Reference fires were considered bark beetle related if at least one MODIS active fire pixel occurred within $1 \mathrm{~km}$ of the edge of an infested site. No buffers were applied to the fire pixels. An unpaired T-test was then used to quantify the relationship between bark beetle infestation and wildfires. This process was repeated with NAIP images and MODIS data ranging from 2002 to 2010 .

\subsection{Early Detection/Mitigation}

\subsubsection{Using Landsat and MODIS to Create Disturbance Index Archives}

This study hypothesized that areas experiencing an ecological disturbance are more susceptible to bark beetle infestation. A combination of MODIS and Landsat satellite imagery were used to generate disturbance indices in the Okanogan-Wenatchee National Forest from 2002 to 2009 (Table 1). If this theory regarding ecological disturbances can be proven, forest managers can then focus their preventative measures on disturbed areas.

Table 1. Satellite indices used to map stress in Wenatchee and Okanogan Forests.

\begin{tabular}{|c|c|c|c|c|c|c|}
\hline \multicolumn{7}{|c|}{ Satellite Indices } \\
\hline Truncation & Name & Index & Satellite / Sensor & Description & Reference & \# \\
\hline Landsat DI & $\begin{array}{l}\text { Landsat } \\
\text { Disturbance Index }\end{array}$ & $D I=$ Brightness $-($ Greenness + Wetness $)$ & Landsat & $\begin{array}{l}\text { tasseled cap based } \\
\text { disturbance }\end{array}$ & $\begin{array}{l}\text { Healey et al., } \\
2005\end{array}$ & 1 \\
\hline
\end{tabular}

The purpose of the disturbance index is to measure vegetation stress that results from any number of natural or human-induced causes such as forest fires or forest insect infestations [11]. The disturbance index exemplifies the contrast between healthy forest stands and bare ground. Disturbance index images were generated for each year between 2002 and 2009 based upon the original reflectance images - brightness, greenness and wetness. Indices were then extracted in ArcGIS 9.3 to calculate average pixel values [12]. Coordinate points from the original seventeen field sites were layered atop each vegetation index from each given year, and $2 \times 2$ pixel values were averaged.

Wildfires often result in charred barren earth. This feature can be detected with a disturbance index. The first index was created using Landsat TM5. The tasseled cap (TC) procedure was used to create a vegetation index that measures three vegetation dimensions - brightness, greenness and wetness [8]. In remote sensing the tasseled cap is used to convert readings [15] in a set of channels into composite values or weighted sums. One of these weighted sums measures roughly the brightness of each pixel [12]. A disturbance index was calculated based upon tasseled cap images from a single date [20].

MODIS data were used to create another Disturbance Index (DI). A prolonged disruption of natural forest functions results in an ecological disturbance. MODIS is adept at detecting natural disturbances in the form of wildfires, storms, or floods, and human-induced disturbances such as agricultural clearing and altering of stream channels. Many of these disturbance events will change ecosystem productivity and resource availability on large scales. When the Land Surface Temperature (LST) and Enhanced Vegetation Index (EVI) contribute anomalies, the MODIS DI is effective at identifying disturbance. Further, the index better represents the normal ecological condition with the addition of further annual mean-maximum values in the denominator [27].

MODIS data were obtained from the Oak Ridge National Laboratory Distributed Active Archive Center (ORNL DAAC) website (http://daac.ornl.gov/MODIS/). Data from years 2002 through 2009 were compiled from the DAAC server. Seventeen data sets were requested — one set for each sampling unit. As delineated by Mildrexler et al. (2007), LST and EVI were used to create the MODIS Disturbance Index (Table 1, 
Equation 2). LST data is gathered from the Aqua/MODIS eight-day composite daytime sensor. EVI data is gathered from the Terra/MODIS 16-day composite sensor. Both indices were cross-referenced with NOAA's archive of weather data to determine if disturbed areas were also moisture stressed. Both Landsat and MODIS indices generated two separate series of disturbance maps from years 2002 to 2009. These maps were overlaid with and compared to NAIP images from each corresponding year, using the same methodology as was described in section 'II Wildfire Analysis.'

Two statistical tests were then run to compare mortality with satellite disturbance indices and contrasting adjacent years' indices. An ANOVA test was run on the data from 2002 to 2009. The purpose is to find a correlation between percent mortality and the indices, so that a model predicting future mortality may be created. The ANOVA compared units were separated into four categories: $0-25 \%$ gray, $25-$ $50 \%$ gray, $50-75 \%$ gray and $75-100 \%$ gray. Unpaired student t-tests were run on significant years to observe the differences. The second set of statistical tests compared adjacent years' indices to see if there was an increase or decrease in value from year to year. We used 2-sample t-tests to compare the index values from each yearly pair.

\subsubsection{Satellite Image Processing-Hyperspectral Detection of the Green Phase}

Research has shown that Landsat TM5 is successful in detecting the red and gray phases of bark beetle attack, but not the green phase [41]. One goal of this study aimed at determining if Hyperion is able to differentiate between the green phase and healthy trees.

Preprocessed Landsat images from 2002 and 2003 were used to train Hyperion data. Previous studies have shown that there is a twelve-month period to reach $90 \%$ red phase from an initial $100 \%$ green phase [41]. Using this information, a supervised minimum distance classification was run on the
Landsat images, searching for green and red trees. This classification used predefined "regions of interest," or ROIs, specific to each year, containing purely green pixels in 2002 and red pixels in 2003. The 2002 and 2003 Landsat classifications were then overlaid to find pixels classified in each year. Forty-six pixels were found and defined as green phase ROIs. The spectra of both green phase and non-green phase pixels were graphed and compared to determine what bands fluctuate with the green phase. Two supervised spectral angle mapper classifications were run on the Hyperion image, using twenty merged green phase ROIs per classification. We compared the two classified images, looking for a correlation between classified pixels. An accuracy of $50 \%$ or higher indicates success [38].

\section{Results}

\subsection{Landsat Classification}

The classification achieved an overall classification score of $80 \%$. However, the classification was only $39.53 \%$ accurate in detecting red and grey-phase forest (Figure 9). Healthy forest, ice and water bodies were identified with greater than $90 \%$ accuracy. Accuracy was calculatsed using the ERDAS Imagine accuracy assessment tool.

\subsection{NAIP Red Phase Algorithm}

NAIP imagery was successful in detecting the extent of the red phase with an accuracy of $96 \%$. Accuracy was measured in ArcGIS by random selection of points located within red tree clusters. This estimates error of commission, but not omission. The total acreage of the study region shown above is $38,481,540$ square meters (Figure 7). In 2006, red phase trees covered 146,188 square meters. By 2009, this number rose to $4,151,500$ square meters.

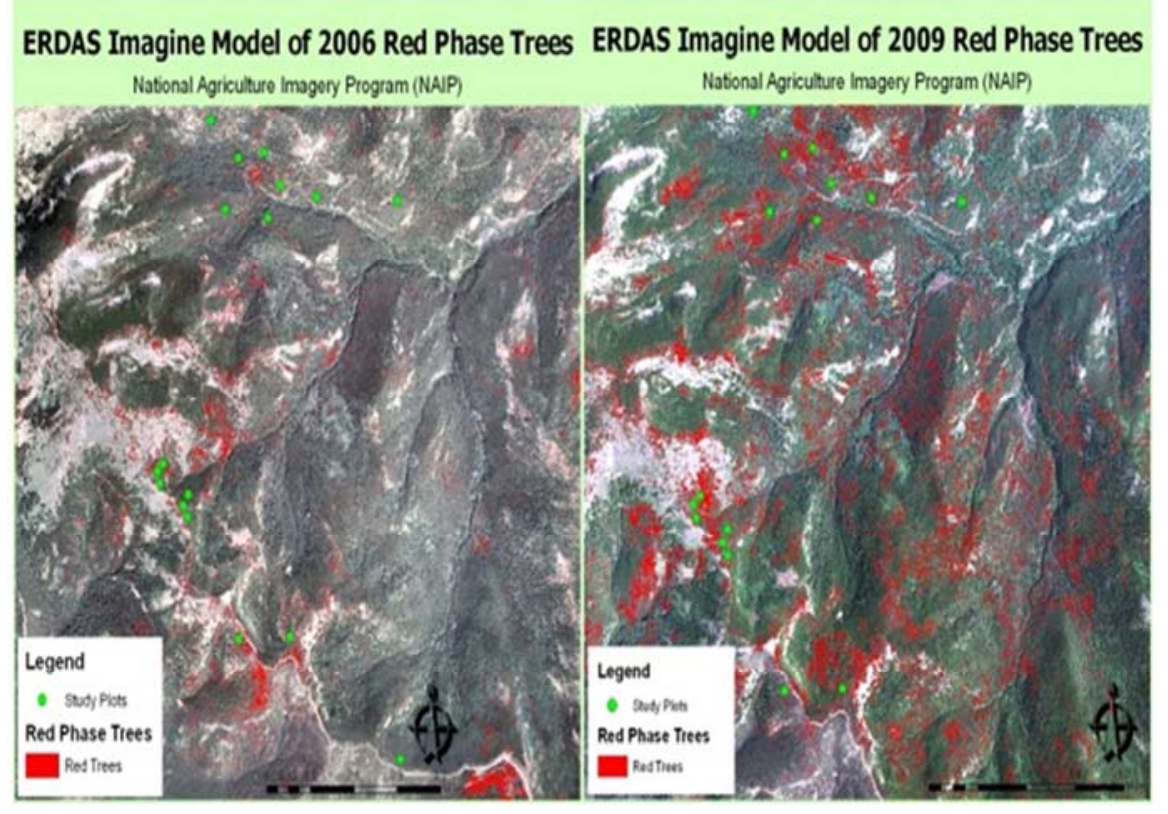

Figure 7. A depiction of red phase trees in aerial photos. 


\subsection{MODIS Fire Analysis}

MODIS detected fires from 2002 to 2010 were directly related to bark beetle infested areas. Over $70 \%$ of MODIS fire pixels occurred on prior-year crown morality pixels. This suggests that the presence of infestation dramatically increases the likelihood of a sizable forest fire. Fire Radiative Power (FRP) was also recorded. (FRP) is a measure of the rate of radiant heat output from a fire. The data were recorded as Aqua MODIS or Terra MODIS fire pixels. When measured individually, Aqua and Terra were less accurate (Table 2). Aqua generally outperformed Terra. Detection rates also increased with fire size. Possibly this is because heavy fuels in western fires [13] may continue to combust after the fire front has passed.

Table 2. Yearly correlation of MODIS fire data and Bark Beetle attack.

\begin{tabular}{llll}
\hline & More Confident Sensor & Fire Radiative Power (FRP): & P Value \\
\hline 2002 & Aqua (A) & A fires are 2\% stronger than T fires & 0.1162 \\
2003 & Aqua & A fires are 18\% stronger than T fires & 0.4239 \\
2004 & Aqua & A fires are 19\% stronger than T fires & 0.1719 \\
2005 & Terra (T) & T fires are 18\% stronger than A fires & 0.1859 \\
2006 & Aqua & A fires are 16\% stronger than T fires & 0.0006 \\
2007 & Aqua & A fires are 5\% stronger than T fires & 0.3886 \\
2008 & Aqua & A fires are 43\% stronger than T fires & 0.1771 \\
2009 & Aqua & Outliers & 0.1010 \\
2010 & Terra & A fires are 22\% stronger than T fires & 0.2444 \\
\hline
\end{tabular}

\subsection{Disturbance Indices}

Disturbed areas correlated with infestation seen in NAIP aerial photos (Table 3). These indices acted like change indices that were particularly sensitive to drought. Each highlighted $\mathrm{p}$ value in Table 3 signifies a correlation with bark beetle infestation. Within the study region, the two disturbance indices were also statistically different from one another in year-to-year comparisons. The years with the greatest differences were 2002 to 2003,2004 to 2005, and 2006 to 2007. 2002 and 2006 had greater levels of vegetation and a lower disturbance index than their respective consecutive years. This data correlates to the drought in 2003 (-2.75 and below) [37].

Table 3. Year to Year Comparisons for Five Indices.

\begin{tabular}{lllll}
\hline & MODIS DI T-test Value & Landsat DI T-test Value & MODIS DI ANOVA Test Value & Landsat DI ANOVA Test Value \\
\hline $2002-2003$ & Increase $p=0.0165^{*}$ & Increase $p=3.3 \mathrm{e}^{-5 *}$ & $\mathrm{p}=0.7100$ & $\mathrm{p}=0.9887$ \\
$2003-2004$ & Decrease $\mathrm{p}=0.0130^{*}$ & Decrease $\mathrm{p}=1.039 \mathrm{e}^{-5 *}$ & $\mathrm{p}=0.1858$ & $\mathrm{p}=0.2830$ \\
$2004-2005$ & Decrease $\mathrm{p}=0.0213^{*}$ & Increase $\mathrm{p}=6.504 \mathrm{e}^{-4 *}$ & $\mathrm{p}=0.3579$ & $\mathrm{p}=0.8470$ \\
$2005-2006$ & Increase $\mathrm{p}=3.439 \mathrm{e}^{-4 *}$ & Increase $\mathrm{p}=0.4129$ & $\mathrm{p}=0.1707$ & $\mathrm{p}=0.3819$ \\
$2006-2007$ & Increase $\mathrm{p}=0.2523$ & Increase $\mathrm{p}=0.0389^{*}$ & $\mathrm{p}=0.0854^{*}$ & $\mathrm{p}=0.3902$ \\
$2007-2008$ & Increase $\mathrm{p}=0.2556$ & Decrease $\mathrm{p}=0.0906^{*}$ & $\mathrm{p}=0.5531$ & $\mathrm{p}=0.8265$ \\
$2008-2009$ & Increase $\mathrm{p}=0.0062^{*}$ & Increase $\mathrm{p}=0.3190$ & $\mathrm{p}=0.8724$ & $\mathrm{p}=0.0410^{*}$ \\
\hline
\end{tabular}

$*$ = statistical significance at the $10 \%$ level

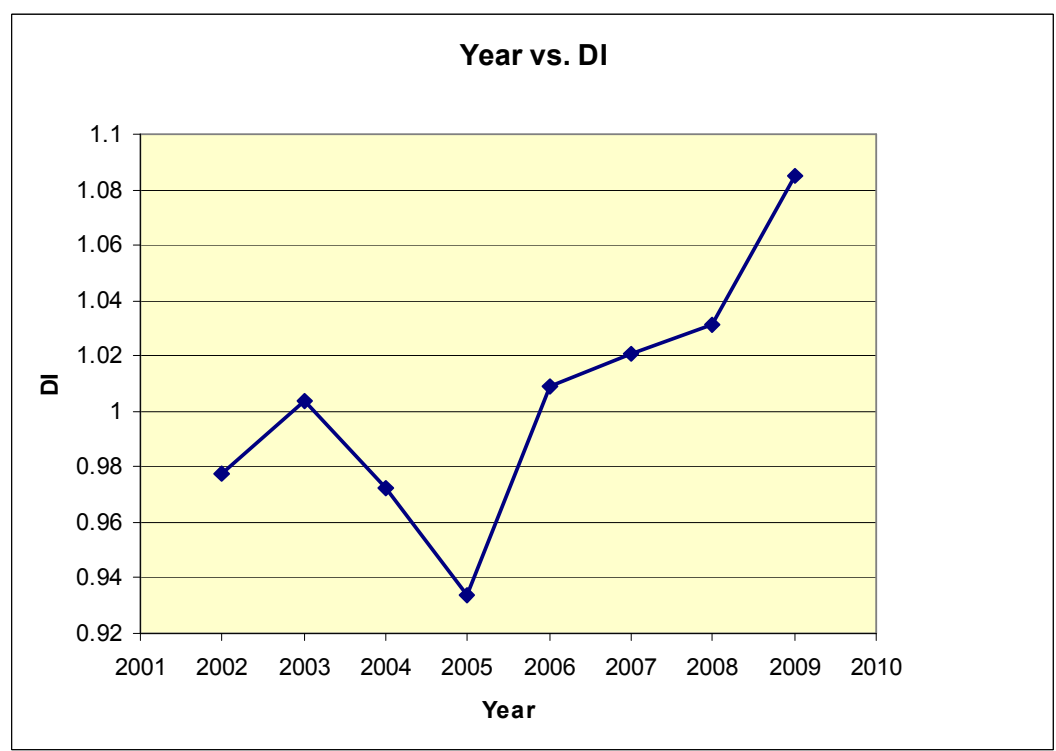

Figure 8. A chart showing average disturbance index values in the Wenatchee National Forest from 2002 to 2009. 
2004 proved to have significant vegetation disturbances in the form of drought and MPB outbreaks. 2004 had significantly lower levels of vegetation yet lower moisture stress than 2003. It also showed lower Landsat disturbance yet higher MODIS disturbance levels than 2003. Since 2002, the MODIS sensor has detected increasing disturbance levels at unhealthy sites, especially between 2006 and 2009 (Figure 8). High mortality sites showed lower Landsat disturbance levels, yet higher MODIS disturbance levels.

\subsection{Detection of the Green Phase}

Hyperion satellite imagery classified the green phase, with a kappa coefficient of 0.1163 , or $11.63 \%$. As the kappa

Healthy Pixels

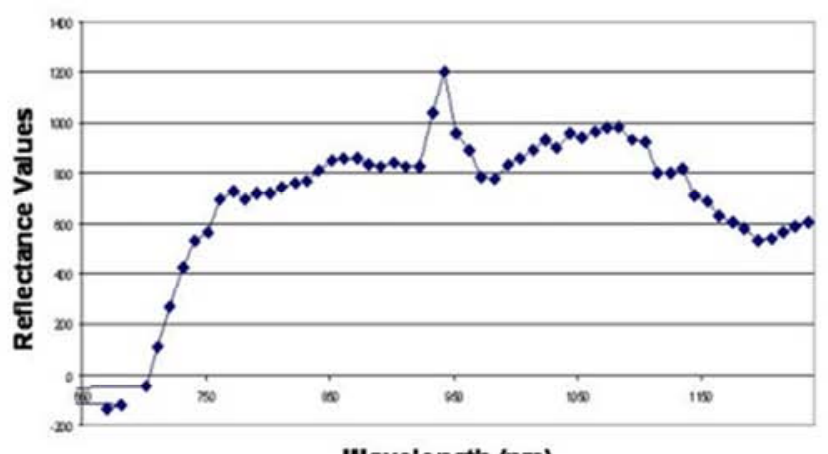

Wavelength $(\mathrm{nm})$ coefficient disregards chance agreement, this was a significant finding. This finding was supported by comparing the spectra of the green phase and healthy trees.

The green phase had higher reflectance values (by approximately $\left.200 \mu \mathrm{W} /\left(\mathrm{cm}^{\wedge} 2 * \mathrm{sr}^{*} \mathrm{~nm}\right)\right)$ between wavelengths of $671 \mathrm{~nm}$ to $1336 \mathrm{~nm}$ (band numbers 32 through 119) (Figure 9). In Cheng, et al., 2010, it was found that the green phase is characterized by its moisture content between wavelengths of $1318 \mathrm{~nm}$ and $1322 \mathrm{~nm}$. These findings indicate that green phase trees display higher reflectance values in the red portion of the spectrum, due to decreased chlorophyll content, and in the infrared portion of the spectrum, due to decreased water content.

\section{Green Phase Pixels}

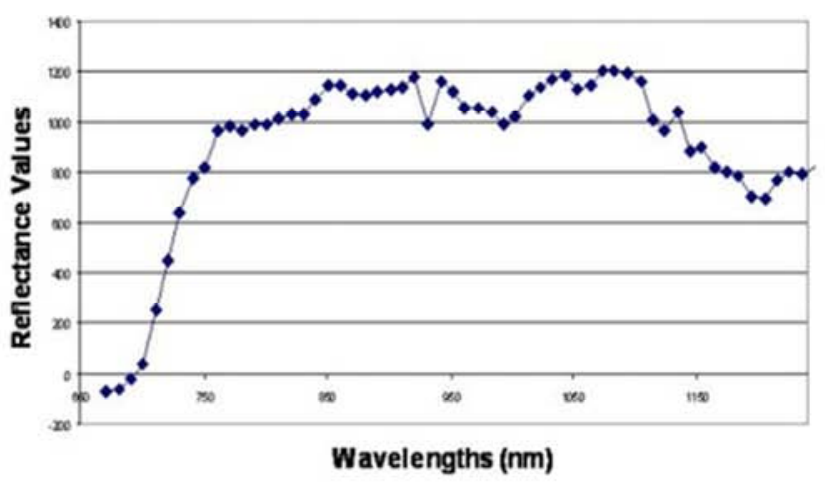

Figure 9. A comparison between the spectral signatures of trees infested with bark beetles and uninfected trees.
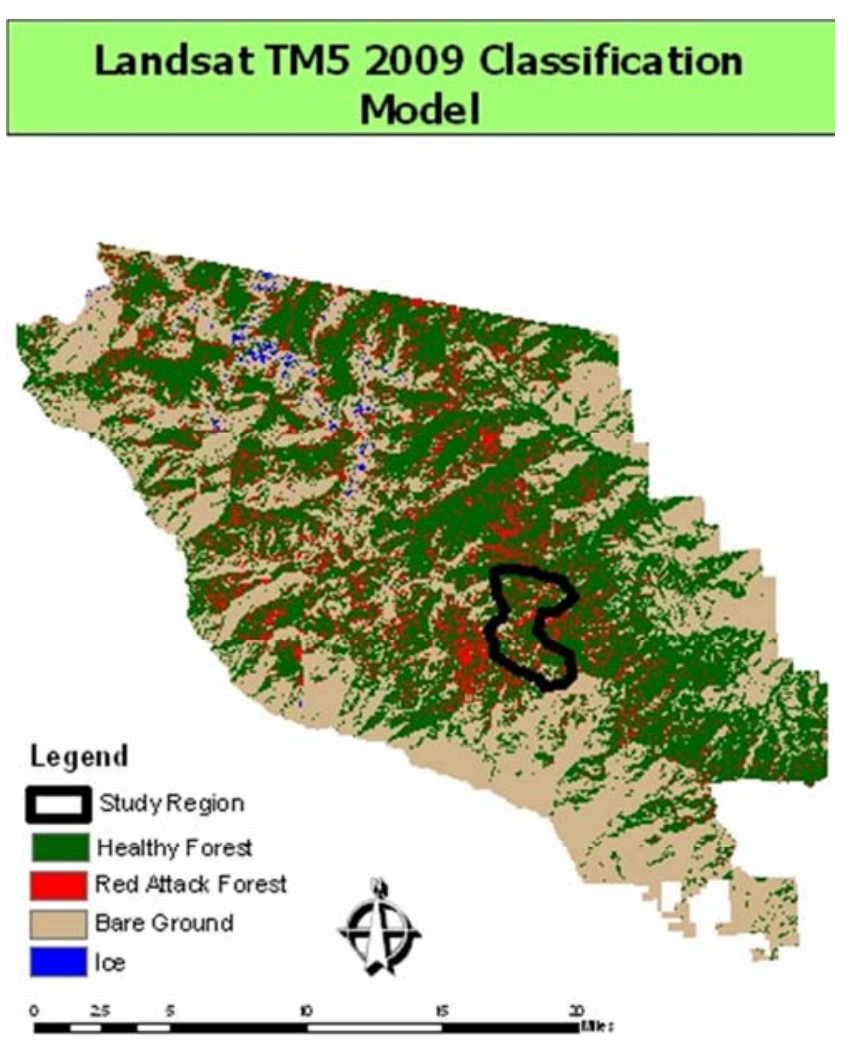

Figure 10. A land use classification of Landsat imagery.

\section{Discussion}

Field measurements and NAIP photos were useful for training satellite data and determining the extent of mountain pine beetle infestation. Classification schemes are an effective way to categorize large areas without detailed imagery (Figure 10). The Landsat classification had an overall accuracy of $80 \%$, yet was only $40 \%$ accurate at detecting the red phase. This is likely due to the $30 \times 30$ meter resolution of the imagery and non-homogeneity of the sample sites. Non-homogenous sites were often inaccurately classified. Inaccurate classifications were the result of border pixels and mixed pixels. If a pixel is $60 \%$ green phase and $40 \%$ red phase, the classification scheme will display it as being entirely green phase. Pixels that occur along the border of different classes are also frequently misidentified.

An algorithm was created to detect the red phase in NAIP imagery. This may be used in tandem with hyperspectral imagery, such as Hyperion, to improve the accuracy of the detection of beetle infestation. The derived NAIP algorithm can be readily modified and used to display red phase trees in any multispectral NAIP image. With this new algorithm, acreage of infested areas can be quickly determined with good accuracy. This information can help the forest service predict future sites of infestation.

Of the MODIS imagery, Aqua detected more fires than 
Terra. The solar diffuser onboard Terra and the response of several bands in the visible spectrum has been degrading a few percent each year and could explain the discrepancy in detection rates [3]. However, the difference in the detection rates between the two MODIS sensors is most likely related to their overpass timing. Fire activity follows a diurnal cycle, often peaking in the afternoon, when weather conditions are ideal for burning. Aqua overpasses in the afternoon, making it ideal for fire detection.

MODIS is effective at identifying large fires, yet errors of omission are considerable. MODIS detects less than one percent of all fires observed on the ground. This means that the problem of bark beetle induced wildfires could be even more severe than the results suggest [14]. Previous studies have established a relationship between wildfires and bark beetle infestations, so the results of this study are not unexpected. Jolly et al. suggests that less heat would be required to ignite the foliage of MPB attacked trees and thus increase crown fire potential in attacked stands. However this correlation is still controversial. Other studies attribute the increase of fires to rising climates and erosion rates [29]. The importance of this study is that it supports the theory of infestations being related to forest fires in the OkanoganWenatchee National Forest.

For the purpose of this study, disturbance indices were used to detect patches of dead vegetation that correlate with regions of extensive bark beetle infestation. This was attempted as a means of early detection. The two disturbance indices strongly correlated with moisture stress, and prove to be very reliable. The Landsat and MODIS spectral indices were fairly accurate in detecting droughts and fires, as checked by NOAA's archive of droughts and wildfires. This study is evidence that spectral indices can be used to predict future areas of infestation.

Hyperion is an efficient tool at detecting the green phase. The accuracy level can be increased by using field work as training data. The Hyperion classification of the green phase also had a low accuracy level, with a kappa coefficient of 0.1163. However, Hyperion was able to detect that the green phase in the reflectance in the red and infrared regions of the electromagnetic spectrum. The higher reflectance in the red region $(620 \mathrm{~nm}$ to $780 \mathrm{~nm})$ may be due to the reduced chlorophyll content of infested trees [2]. Trees with lower chlorophyll content tend to reflect rather than absorb red wavelengths [43]. Therefore, infested trees will have a higher red reflectance level than healthy trees. The higher infrared reflectance is caused by decreased water flow to the crown, due to the burrowing of the bark beetles [17]. Hyperion's ability to detect the spectral differences between green and other phase trees indicates that Hyperion may be used to detect the green phase. It may also be a strong predictor of the red phase, with its hyperspectral capabilities. Future studies should focus on using Hyperion data to more accurately classify the incipient green phase. The green phase can be accurately detected with extensive field work and high resolution NAIP images, both of which can be used to train an accurate supervised classification.

\section{Conclusion}

The methodology followed a linear progression of detection, fire association and then early detection/prevention. Field work, the Landsat classification and the NAIP algorithm were used to detect infested sites in the study area. These infested sites were then overlaid atop MODIS fire data to establish a link between infestation and wildfires. Once the link was established, attention then turned to mitigation efforts like the spectral indices and Hyperion classification.

Remote sensing is a valuable tool in fire mitigation and tracking bark beetle infestation. However, the size of fires and infested areas tends to be small relative to satellite resolution. Thus, high spatial resolution imagery is optimal. Resolution of the aforementioned satellites was sufficient, but more detailed imagery would yield better results for the spectral indices. The multispectral indices proved to be accurate at detecting infestation. This is because moisture content, vegetation levels, fire and ecosystem disturbance are all related to infestation. Multiple measurements per field sampling site would likely yield more significant results.

Bark beetle infestations are theoretically related to wildfires. Predicting future sites of infestation is necessary to mitigate the severity of future wildfires. Hyperion data can differentiate between the red and infrared portions of the spectra of green phase trees and healthy trees. Hyperion, therefore, shows promise at detecting the incipient green phase, although further research should be done to increase the accuracy of Hyperion's classification of the green phase. Through the usage of field work, spectral indices, and NAIP imagery, bark beetle infestation can be detected so that any necessary mitigation steps can be taken.

\section{Acknowledgements}

We would like to sincerely thank our advisor Travis Freed of the US Forest Service for his detailed knowledge of the local geography. We also thank Dr. Jennifer Dungan, Lee Johnson, Brad Lobitz, and Dr. Charles Williams for their assistance with GIS and remote sensing. We thank Drs. Vern Vanderbilt and Philip Hammer for comments on earlier drafts of this manuscript.

\section{References}

[1] N. Axelson, "Influence of fire and mountain pine beetle on the dynamics of lodgepole pine stands in British Columbia, Canada. Forest Ecology and Management," 257, pp. 1874$1882,2009$.

[2] F. J. Ahern, "The effects of bark beetle stress on the foliar spectral reflectance of lodgepole pine," International Journal of Remote Sensing, vol. 9, no. 9, pp. 1451-1468, 1988.

[3] W. Barnes, X. Xiong, and V. Salomonson, "Status of Terra MODIS and Aqua MODIS," Advances in Space Research, vol. 32, no. 11, pp. 2099-2106, 2003. 
[4] G. Chander, and B. Markham, "Revised landsat-5 TM radiometric calibration procedures and post-calibration dynamic ranges," IEEE Transactions on Geoscience and Remote Sensing, vol. 41, no. 11, pp. 2674-2677, 2003.

[5] T. Cheng, B. Rivard, G. A. Sanchez-Azofeifa, J. Feng, and M. Calvo-Polanco, "Continuous wavelet analysis for the detection of green attack damage due to mountain pine beetle infestation," Remote Sensing of Environment, vol. 114, pp. 899-910, 2010.

[6] S. B. Coggins, N. C. Coops, M. Wulder, C. Bater, and S. M. Ortlepp, "Comparing the impacts of mitigation and nonmitigation on mountain pine beetle populations," Journal of Environmental Management, vol. 92, pp. 112-120, 2011.

[7] G. Cottam, (1953). Some Sampling characteristics of a population of randomly dispersed individuals. Ecology, vol. 34, no. 4, Retrieved from http://www.jstor.org/stable/1931337.

[8] E. P. Crist, and R. Kauth, "The tasseled cap de-mystified," Photogrammetric Engineering \& Remote Sensing, vol. 52, no. 1, pp. 81-86, 1986.

[9] E. Esin, and O. Uslu, "Assessment of the effects of agricultural practices on non-point source pollution for a coastal watershed: A case study Nif Watershed, Turkey," Ocean \& Coastal Management, vol. 51, pp. 601-611, 2008.

[10] M. Garrison-Johnston, J. Moore, S. Cook, and G. Niehoff, "Douglas-fir beetle infestations are associated with certain rock and stand types in the inland northwestern United States," Community and Ecosystem Ecology, vol. 32, no. 6, pp. 1354-1363, 2003.

[11] M. Hais, M. Jonasova, J. Langhammer, and T. Kucera, "Comparison of two types of forest disturbance using multitemporal landsat TM/ETM+ imagery and field vegetation data," Remote Sensing of Environment, vol. 113, pp. 835-845, 2009.

[12] T. Han, M. Wulder, J. White, N. Coops, M. Alvarez, and C. Buston, "An Efficient protocol to process landsat images for change detection with tasselled cap transformation," IEEE Geoscience and Remote Sensing Letters, vol. 4 no. 1, pp. 147$151,2007$.

[13] S. J. Hart, T. Schoenngal, T. Veblen, and T. B. Chapman, "Area burned in the western United States is unaffected by recent mountain pine beetle outbreaks," PNAS, vol. 112 no. 14, pp. 4375-4380, 2015.

[14] T. J. Hawbaker, V. Radeloff, A. Syphard, Z. Zhu, and S. I. Stewart, "Detection rates of the MODIS active fire product in the United States," Remote Sensing of Environment, vol. 112, pp. 2656-2664, 2008.

[15] S. Healey, W. B. Cohen, W. Zhiqiang, and O. N. Krankina, "Comparison of Tasseled Cap-based Landsat data structures for use in forest disturbance detection," Remote Sensing of Environment, vol. 97, pp. 301-310, 2005.

[16] P. Hessburg, J. K. Agee, and J. F. Franklin, "Dry forests and wildland fires of the inland Northwest USA: Contrasting the landscape ecology of the pre-settlement and modern eras," Forest Ecology and Management, vol. 211, pp. 117-139, 2005.

[17] A. J. Hicke, and C. J. Jenkins, "Mapping lodgepole pine stand structure susceptibility to mountain pine beetle attack across the western United States," Forest Ecology and Management, vol. 255 , pp. 1536-1547, 2008.

[18] C. Hsu, and L. Johnson, "Multi-criteria wetlands mapping using an integrated pixel-based and object-based classification approach," Colorado Department of Transportation, CDOT, 2008.

[19] J. Jensen, 2007. Remote Sensing of the Environment an Earth Resource Perspective, edited by D. Kaveney, J. Howard, K. Schiaparelli, and E. Thomas. Upper Saddle River, NJ: Pearson Prentice Hall.

[20] S. Jin, and S. Sader, 2005. "Comparison of time series tasseled cap wetness and the mormalized difference moisture index in detecting forest disturbances," Remote Sensing of Environment, vol. 94, pp. 364-372, 2005.

[21] M. Johnson, G. Kohler, D. Omdal, A. Ramsey-Kroll, B. Hostetler, R. Mathison, and A. Nelson, (2010). "Forest health highlights in Washington-2009," USDA.

[22] M. W. Jolly, R. Parsons, A. Hadlow, G. Cohn, S. McAllister, J. B. Popp, R. Hubbard, and J. Negron, "Relationships between moisture, chemistry, and ignition of Pinus contorta needles during the early stages of mountain pine beetle attack," Forest Ecology and Management, vol. 269, pp. 52-59, 2011.

[23] D. Kulakowski, and D. Jarvis, "The influence of mountain pine beetle outbreaks and drought on severe wildfires in northwestern Colorado and southern Wyoming: A look at the past century," Forest Ecology and Management, vol. 262, pp. 1686-1696, 2011.

[24] D. Leatherman, I. Aguayo, and T. Mehall, (2007). Mountain pine beetle. Insect Series, vol. 5 (528), Colorado State University Press.

[25] H. J. Lynch, R. Renkin, R. Crabtree, and P. R. Moorcroft, "The Influence of Previous Mountain Pine Beetle (Dendroctonus ponderosae) Activity on the 1988 Yellowstone Fires," Ecosystems, vol. 9, pp. 1318-1327, 2006.

[26] G. W. Meigs, R. Kennedy, A. Gray, and A. J. Gregory, "Spatiotemporal dynamics of recent mountain pine beetle and western spruce budworm outbreaks across the Pacific Northwest Region,” vol. 339 no. 1, pp. 71-86, 2015.

[27] D. Mildrexler, M. Zhao, F. Heinsch, and S. Running, "A new satellite-based methodology for continental scale disturbance detection," Ecological Applications, vol. 17 no. 1, pp. 235$250,2007$.

[28] J. D. Miller, S. Danzer, J. Watts, S. Stone, and S. Yool, "Cluster analysis of structural stage classes to map wildland fuels in a madrean ecosystem," Journal of Environmental Management, vol. 68 no. 3, pp. 239-252, 2003.

[29] J. D. Miller, H. D. Safford, M. Crimmins, and A. E. Thode, "Quantitative Evidence for Increasing Forest Fire Severity in the Sierra Nevada and Southern Cascade Mountains, California and Nevada, USA," Ecosystems, vol. 12, pp. 1632, 2009.

[30] K. Mitchell, (2007). Quantitative analysis by the pointcentered quarter method. Hobart and Williams Smith Colleges.

[31] J. Moore, P. Mika, J. Schwandt, and T. Shaw, "Nutrition and forest health," Interior Cedar-Hemlock-White Pine Forests: Ecology and Management, 1993. 
[32] K. Niemann, and F. Visintini, (2005). "Assessment of potential for remote sensing detection of bark beetle-infested areas during green attack: a literature review," Natural Resources Canada, Mountain Pine Beetle Initiative Working Paper 2005-2.

[33] J. T. Parker, M. Clancy, and L. Mathiasen, "Interactions among fire, insects and pathogens in coniferous forests of the interior western United States and Canada," Agriculture and Forest Entomology, vol. 8, pp. 167-189, 2006.

[34] L. Perez, and S. Dragicevic, "Modeling mountain pine beetle infestation with an agent-based approach at two spatial scales," Environmental Modeling \& Software, vol. 25 no. 2, pp. 223-236, 2009

[35] J. Rouse, R. Haas, J. A. Schell, and. D. Deering, "Monitoring vegetation systems in the Great Plains with ERTS," Proceedings of the Third Earth Resources Technology Satellite-1 Symposium, NASA, Greenbelt, MD, pp. 301-317, 1974.

[36] L. Sampedro, X. Moreira, P. Martins, and R. Zas, "Growth and nutritional response of Pinus pinaster after a large pine weevil (Hylobius abietis) attack,” Trees, vol. 23, 2009.

[37] State of the Climate drought, annual 2005. (2009). National Oceananic and Atmospheric Administration.

[38] S. Subramanian, N. Gat, M. Sheffield, J. Barhen, and N. Toomarian, "Methodology for hyperspectral image classification using novel neural network," Algorithms for Multispectral and Hyperspectral Imagery III, SPIE, pp. 3071, 1997.
[39] United States Department of Agriculture, Natural Resources Conservation Service. 2008. Soil Survey of Okanogan National Forest Area, Washington. Accessible online at: http://soils.usda.gov/survey/printed_surveys/.

[40] Washington State Department of Natural Resources, (Photographer). (2010). USGS 100k quad: twisp- a148120. [Web].

[41] J. White, N. Coops, T. Hilker, M. Wulder, and A. Carroll, "Detecting mountain pine beetle red attack damage with EO-1 Hyperion moisture incides," International Journal of Remote Sensing, vol. 28 no. 10, pp. 2111-2121, 2007.

[42] M. J. Wingfield, E. Brockerhoff, B. D. Wingfield, and B. Slippers, "Planted forest health: The need for a global strategy," Science, vol. 349, pp. 832-836.

[43] M. A. Wulder, J. White, N. Coops, T. Han, M. Alvarez, C. Butson, and X. Yuan, "A Procedure for mapping and monitoring mountain pine beetle red attack forest damage using landsat imagery," Canadian Forest Service, BC-X-404, 2006.

[44] Q. Zhang, E. Middleton, Y. Cheng, K. Huemmrich, B. Cook, L. Corp, W. Kustas, A. Russ, J. Prueger and T. Yao, "Integrating chlorophyll fAPAR and nadir photochemical reflectance index from EO-1/Hyperion to predict cornfield daily gross primary production," Remote Sensing of Environment, vol. 186, no. 1, pp. 311-321. 